\title{
A Study on Formation of Rural Architectural Space Image Based on the Physical Environment
}

\author{
Changyou $\mathrm{Wu}^{1, \mathrm{a}^{*}}$, Xiaojun Zhang ${ }^{2, \mathrm{~b}}$,Yan Chen $^{3, \mathrm{c}}$ \\ ${ }^{1}$ Wuhan University of Science and Technology, China \\ ${ }^{2}$ Wuhan University of Science and Technology, China \\ ${ }^{3}$ Wuhan University of Science and Technology, China \\ a323201796@qq.com, b972045422@qq.com, c2385960727@qq.com
}

\begin{abstract}
Key Words: Rural Buildings; Space Image; Spatial form; Ecological Construction; Green Environment

Abstract: Rural architectural space image presents in the physical environment such as spatial form, characteristics of modeling, material texture, color and functional layout. Combining the examples presented in the physical environment, this paper summarizes the formation modes of rural architectural space image, and discusses the formation rules of rural architectural space image in the physical environment, which has practical guiding significance in the process of urbanization to realize the characteristic natural and ecological environment in rural areas.
\end{abstract}

\section{Introduction}

Rural buildings are much smaller than urban buildings in terms of architectural scale and size, but in architectural design, they have distinctive features in terms of architectural spatial form, architectural modeling, material texture, functional layout, architectural color, and ecological environmental protection. In the process of urbanization, rural architectural design should be explored deeply in the above respects, so as to enrich architectural design of villages and towns, to realize new rural natural and ecological landscape with distinctive features.

\section{Spatial form and "Path" Characteristic Image}

In China, villages and towns are widely distributed, and the natural environment such as climate and topography is characterized by diversity. Under the guidance of rural planning, rural spatial form is easy to realize its overall flexibility and diversity. In general, rural buildings are low-rise buildings, namely, one or two floors at least, three to five floors at most. Due to different geographical position, topography and historical background, rural architectural spatial forms are different from each other. The author will make an analysis of four types of rural buildings respectively, namely, from perspectives of mountain villages, towns and cities, villages and towns in the Yangtze River Delta, villages and towns in the plain, historical towns:

(1) In mountain cities, the buildings are built along the slope near the mountain, and look magnificent (Fig. 1, 2, 3). Individual buildings are built along the slope, arranged neatly in twists and turns, and are characterized by clear layout in the overall space, combination of empty with reality, and colorful forms. 
2)

In

villa

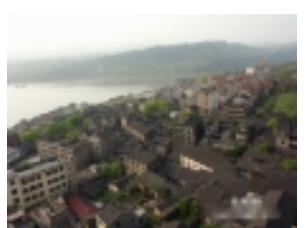

Fig. 2 Aerial view of Xituo ancient town

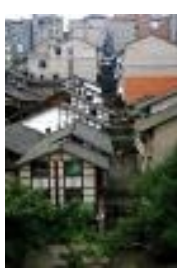

Fig. 3 Yunti Street's spatial form

ges and towns in the Yangtze River Delta, rivers and lakes are dotted everywhere, and waterways are interconnected (Fig. 4). With water flow as axis, the buildings here look like a strip or a mesh. Group space varies with water flow, wide or narrow, open or closed; individual space extends with water flow, nearby or far, deep or shallow. Clouds linger around villages, presenting a layer of mist like tough silk or yarn, and town space shows the flow trend, namely, landscape changes with moving paces. Villages and towns in the Yangtze River Delta have the characteristics of "you have to take a boat to call at your friends, even they live nearby". In Zhouzhuang (as shown in Fig. 5, 6), for example, the riverway is in the shape of Chinese character “井”, the buildings are built by water, and streets extend along rivers, simple and plain. Just like you travel in a poem or picture world, at water alleys is an ocean of people, on rivers people row a boat.

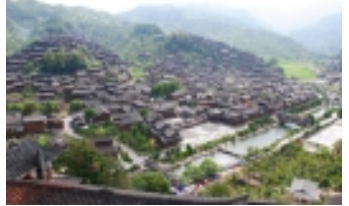

(3)

In the

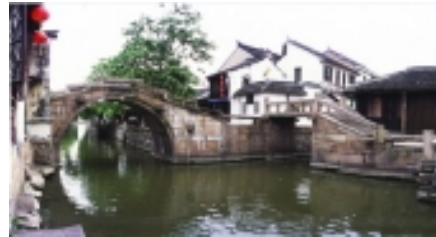

Fig. 5 Twinbridge in Xhouzhuang

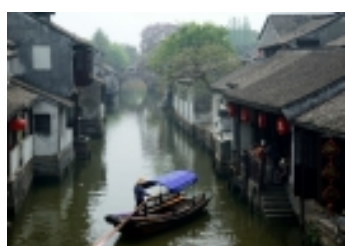

Fig. 6 Zhouzhuang ancient town

plain, villages in Xijiang Town

rural buildings adopt townhouse layout or single folks house layout (Fig. 7, 8, 9), where there are green shade, garden and patio, integrating the buildings and nature, so the whole villages and towns are in the spatial form with a strong sense of rhythm and order. In the plain, the land is flat, and ancestors ever lived here a long time ago. The plain has a long history and less limiting factors, easy for construction, so it has the characteristics of form changes and deep humanities, as shown in Table 1. 
Table 1 Classification of rural buildings in the plain ${ }^{[1]}$

\begin{tabular}{|l|l|}
\hline Classification & Architectural features \\
\hline \multirow{5}{*}{$\begin{array}{l}\text { Natural } \\
\text { villages }\end{array}$} & $\begin{array}{l}\text { They were formed spontaneously, and basically had no planning. } \\
\text { alleys are distributed in the shape of cross or square grid. However, in } \\
\text { the agricultural region of southern China, households per village are } \\
\text { increased gradually, without fixed orientation. } \\
\text { In northern China, the overall layout is often in the shape of Chinese } \\
\text { character "-". But in southern China, most of peasant households live } \\
\text { nearby farmland, so villages were formed spontaneously. }\end{array}$ \\
\hline Clan villages & $\begin{array}{l}\text { In China, clan villages are widely distributed, esp. in the south. Clan } \\
\text { villages emerged under the family system where a clan lives together, } \\
\text { and are divided into two types, namely, village of a big family living } \\
\text { for generations and village of a clan living together. The former } \\
\text { basically disappeared after new China was founded; the latter has the } \\
\text { construction planning, and the drawing for planning and design of the } \\
\text { whole village is shown in the genealogy. }\end{array}$ \\
\hline \multirow{5}{*}{$\begin{array}{l}\text { Enclosed- } \\
\text { castled } \\
\text { villages }\end{array}$} & $\begin{array}{l}\text { (1) In the village of a clan living together, for the sake of safety, } \\
\text { clansmen allocated and used land according to the unified planning, } \\
\text { and built the enclosures and castles, for example, Hakka earth buildings } \\
\text { in the south of Fujian Province, Hakka enclosed building in the south of } \\
\text { Jiangxi Province, etc.; } \\
\text { (2) In the village of different clans living together, these enclosures and } \\
\text { castles were built according to local conditions, in various shapes and } \\
\text { forms; meanwhile, the castle gate and street lanes are in the appropriate } \\
\text { relationship, for example, Diji, Yangcheng County, Shanxi Province, } \\
\text { etc. }\end{array}$ \\
\hline
\end{tabular}

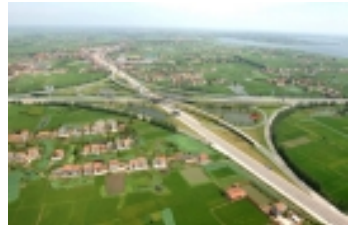

Fig. 7 Residences in the middle-lower Yangtze River plain

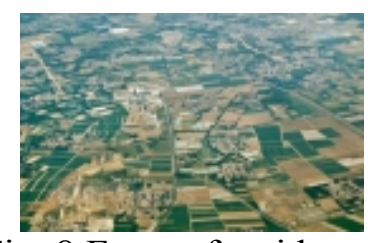

Fig. 8 Form of residences in north China plain

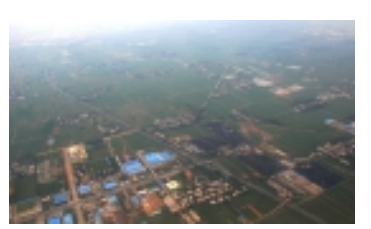

Fig. 9 Form of villages in the Central Shaanxi Plain

(4) Due to profound historic culture, there are traditional buildings in historical towns. Architectural groups are usually connected through "courtyards", so spatial sequence is open and closed, and has strong rhythm and rich layers. These villages and towns have their own space characteristics, and the diversity, flexibility and interest of its spatial form are superior to those modern urban building. In line with the principle of the harmony between building and nature, in the urbanization of rural architectural design, the spatial form produced through combining individual buildings with group buildings must be full of variety.

Let us take architectural features of Fenghuang Ancient Town as an example (as shown in Fig. 10). 
Streets of Fenghuang Ancient Town were built along the river and formed into the natural street system ${ }^{[2]}$. Fenghuang Ancient Town is reasonable and compact in terms of architectural layout, integrating with mountainous environment. Natural resources have been efficiently utilized here, which fully shows ancient Chinese had a profound understanding of architecture and environment. Individual building has the style of the Ming and Qing dynasties. And carved patterns on wooden windows show the flavor of the western Hunan Province. (Fig. 11) As the Miao traditional architecture, stilted buildings are considered as the best form of ecological architecture by modern architects. Cedar wood is used as support on the rock in the river or by the river, forming a rolling outline with the tall gate tower. The buildings were built leaning against mountains, presenting 3D features in space; the multi-view building mode enriches spatial level, so the buildings present high-low space landscape. Furthermore, when you roam on "S"-shaped ancient streets (as shown in Fig. 12), you cannot take in everything at a glance from the horizontal and facade perspectives, but sections of small semi-enclosed space are formed. Streets are considered as a transition part of connecting public space to private space, each public space is relatively independent, not easy to be disturbed by other space and activities. A large public space is divided into a number of semi- public space, this handling technique not only increases the privacy protection, but also creates conditions for roam activities.

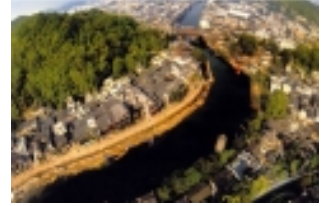

Fig. 10 Aerial view of

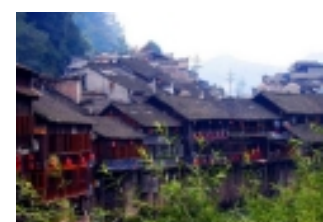

Fig. 11 Stilted buildings

Fenghuang Ancient Town

\section{Individual Building Modeling and "Joint" Landscape Image}

China covers a large territory, from the point of geographical location and natural environment, rural architectural modelings are different in the east-central-west regions, the mountains and the plains; from the point of cultural background and economic level, rural buildings are in different development stages at the same time, and show local features. Therefore, the way to realize new rural architectural modeling should be diversified, and focusing on or even only a single way is not allowed ${ }^{[3]}$. In China, villages and towns should have their own characteristics, and their diversities should be highlighted.

Beautifully-shaped, unique buildings shock people visually. Due to its small size, simple structure, covering a large land and abundant national resources, rural buildings have a broader space than urban buildings in terms of architectural modeling. Attention should be paid to the following aspects in the design.

(1) Modeling should be harmonious with the surrounding environment as far as possible, and keep natural outline, in order to obtain the best natural landscape. This coordination method is adopted without destroying natural terrain, and its material, color, framework, symbols and size should match with the surrounding environment.

(2) Modeling should co-exist and integrate with regional climate, to ensure the harmony of architecture and environment. For example, the buildings nearby water or on the slope should not affect the natural environmental landscape, on the basis of respecting the living habits of the natives, the modeling scheme for residences and other individual building should be implemented, so that the buildings can be suitable for local climate, and form their own unique style. It is cold in northern China, and residents need abundant sunshine, so the principal room should face to the south as far as possible. Due to cold weather, the buildings have thick wall in north China, and building entities look heavyweight and cumbersome, so it is not easy to create concave and convex. Architectural space is restricted, so individual building is in a regular shape. Conversely, it is hot in southern 


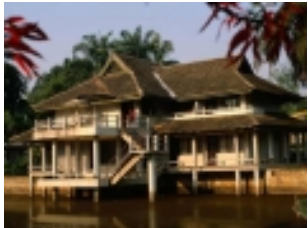

Fig. 13 New Dai dwelling houses in

Xishuangbanna, Yunnan

Province

China, folk houses (figure 13) have light and thin walls and roof, and its roof slope is bigger than that of folk houses in northern China, convenient for drainage. Individual building makes people feel lightweight and exquisite; architectural space can be extended freely, and ventilated flexibly.

(3)Modeling should be coordinated with folk customs, absorb traditional local "symbols" and "style", and remove the negatives. In the construction of new rural district or in the reconstruction of traditional old streets, new buildings should be consistent with old buildings in the aspect of cultural tradition. But new buildings or reconstructed buildings shall not copy old buildings completely. The "symbols" and "style" of old buildings should be extracted and be applied to the construction or reconstruction of buildings, in order to achieve the harmony of old and new buildings.

\section{Material Texture and "Region" Characteristic Image}

Material is the main carrier to constitute hard architectural landscape, and the characteristics of rural architecture are greatly affected by material texture (Fig.15). Different material textures give people different visual and psychological perceptions. For example, wooden surface gives people a warmth, soft feeling; rough stone gives people a rough, bold and uninhibited feeling; dry earth wall face, however, give people a plain, natural feeling; glass and metal bring a bright, clean and modern feeling. With the development of material science, some new materials emerge rapidly. As a result, many buildings may lose their original individuality and charm. In order to make new buildings have traditional characteristics, local materials should be first selected in the design. "Advanced" materials disharmonious with the environment shall not be selected, to prevent pursuing fashion and luxury blindly. The selection of local material has three advantages: one is to adjust measures to local conditions, convenient for selection of materials; two is to accord with local habits, customs and practice; three is to coordinate with the surrounding environment. In villages and towns, there are rich resources of building materials, and to apply local materials in construction is one of the important ways to achieve rural architectural features.

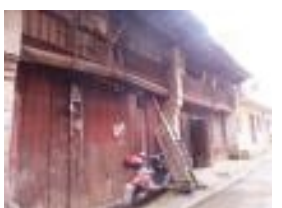

Wooden surface

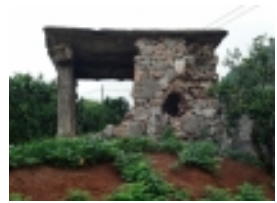

Stone

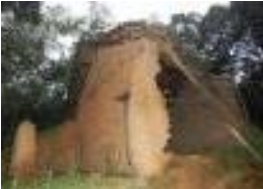

Earth wall

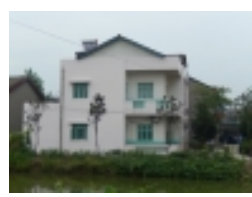

Paint

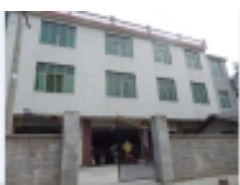

Face brick

Fig. 14 Folk houses made up of different materials

\section{Functional Layout and "Boundary" Characteristic Image}

Rural buildings serve for villages, and the needs of rural life should be considered in the group and individual functional layout. Nowadays, most of rural buildings have been built along the road or along the river, each building highlight its own characteristics. Rural buildings are in different heights and shapes, and lack of public space; old buildings are mixed with new buildings, in sharp contrast. All kinds of cables extend freely in the sky, and advertising slogans stand everywhere; garbage and sewage are discharged freely, etc. In terms of group functional layout, therefore, settlements should be selected reasonably, and an overall planning should be made for the rural community, showing its beautiful landscape, public and production space should be reasonably arranged, including farmers' markets, 
grain supply center, livestock market, assembly place and various agricultural food processing factories. In terms of individual building design, for example, the following factors should be considered in the design of residential buildings: One is the mode of production; two is traditional living habits and social activities; three is aesthetic taste and faith. Specifically speaking, residents generally require enough indoor height, reflecting their psychological needs of self-improvement; a large living room (main room) meets the needs of dropping round; a big roof terrace meets the needs of enjoying the cool and drying agricultural by-products. Sloping roof and courtyard are popular among the residents. Sloping roof has an effect of heat insulation in southern China, and can be used to set up a layer of thermal insulation in northern China. Courtyard (patio) can be used for planting and enjoying the cool, etc., as well as for privacy protection. In urban households, religious requirements of some residents should be considered as well, so the religious hall is required to set up. With the further improvement of living standard of rural residents, storefronts and truck parking place should be considered in the residential design.

\section{Architectural color and "Symbol" Characteristic Image}

With the increase of economic level and the promotion of national aesthetic taste, rural buildings present phased characteristics in terms of color and form. In color application, attention should be paid to the uniformity of most tone and difference of individual building tone. In a town, Songzi, Hubei Province (Fig. 15), for example, residential buildings are in the majority of rural buildings, while public buildings are in the minority. There are the common problems existing in China's rural buildings in this town. Ceramic tiles are used everywhere; the use of color is in a disorder, and focuses on each color's uniqueness, or color is dull, lack of lasting appeal, and has a unified style. In the new rural construction, therefore, we should actively learn the methods to use color in ancient buildings, for example, white wall and black tiles are used to set off red-lacquered door and golden titles. In modern rural construction, attention should be paid to color application, to reflect regional individuality and commonness. Through using local material color, rural buildings have not only a large area of background color, but accent color of a few public buildings. Both of them complement each other, set each other off, and jointly constitute the harmony of rural architectural color.

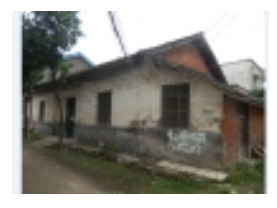

1970s

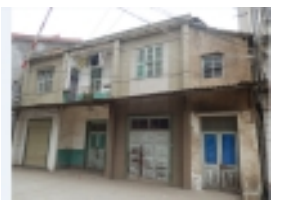

$1980 \mathrm{~s}$

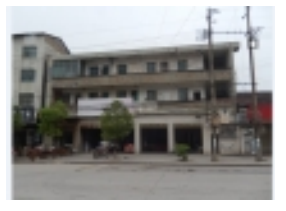

$1990 \mathrm{~s}$

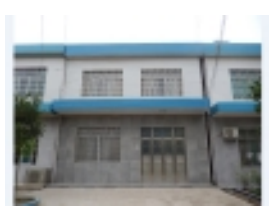

2000s

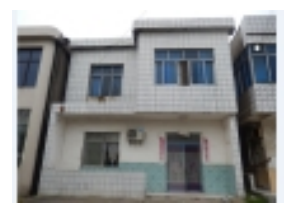

After new China was founded

Fig. 15 Residential building during different periods

\section{Conclusions}

With today's rapid development of urbanization, rural reconstruction and construction, in the process of formation of rural characteristics, rural architecture is designed according to the above aspects such as spatial form, architectural modeling, material texture, architectural color and ecological environmental protection, to lay a solid foundation for the formation of rural architectural characteristics. We should integrate theory with practice, make the best use of the circumstances, make scientific layout and design, highlight rural buildings' service functions for villages and towns, build and improve rural infrastructure and public service facilities in accordance with the law, and improve 
the quality of residents' living environment, form the characteristic rural environment, to realize the harmonious development of urban and rural areas.

\section{References}

[1] Li Baihao, Wan Yanhong. Chinese Rural Architectural Culture [M]. Wuhan: Hubei Education Press, 2008:7.

[2] Ao Qizong. Analysis on Spatial Form and Dynamic Factors of Fenghuang Ancient Town [J]. China Homes, 2012 (2): 250.

[3] $\mathrm{Wu} \mathrm{Lu}$. Discussion on the Connotation of New Urbanization [J]. Urban Construction Theory Research (electronic version), 2013 (24).

[4] Wu Hao. Study on New Intensive, Intelligent, Green and Low-carbon Urbanization Path in the Central Plains Economic Zone [J]. Journal of Statistics and Management, 2014 (4): 60.

[5] Liu Dianhua. Architecture Design of Village and Town [M]. Nanjing: Southeast University Press, 1999.6. 